\title{
Supplements and refinements to current classifications and nomenclature of the fronto-ethmoidal transition region by systematic analysis with 3D CT microanatomy*
}

\author{
S.J. Zinreich', F.A. Kuhn², D. Kennedy³, M. Solaiyappan'1, A Lane', \\ N.R. London Jr. ${ }^{4}$, W. Hosemann ${ }^{5}$ \\ 'The Russel H. Morgan Departments of Radiology, The Johns Hopkins Medical Institutions, Baltimore, MD, USA \\ ${ }^{2}$ The Georgia Nasal and Sinus Institute Savannah, GA, USA \\ ${ }^{3}$ The Department of Otorhinolaryngology Head and Neck Surgery, the Perelman School of Medicine University of \\ Pennsylvania, Philadelphia, PA, USA \\ ${ }^{4}$ The Department of Otorhinolaryngology Head and Neck Surgery, The Johns Hopkins Medical Institutions, Baltimore, MD, USA \\ ${ }^{5}$ Department of Otorhinolaryngology-Head and Neck Surgery, University of Greifswald, Germany
}

Rhinology Online, Vol 4: 165 - 180, 2021

http://doi.org/10.4193/RHINOL/21.039

*Received for publication:

August 10, 2021

Accepted: August 23, 2021

Published: August 31, 2021

\begin{abstract}
Objective: The microanatomy of the fronto-ethmoidal transition region has been addressed in several classifications. CT stereoscopic imaging (3DCTSI) provides improved display and delineates three defined complex "spaces", the Frontal Sinus/Frontal Recess Space, the Infundibular Space of the Ethmoid Uncinate Process, and the Ethmoid Bulla Space (FSRS, IS-EUP, EB), none of which were adequately described with the "cell" terminology. We present details on the 3D microanatomy, variability, and prevalence of these spaces.
\end{abstract}

Methods: 3D stereoscopic imaging displays (3DCTSI) were created from 200 datasets. The images were analyzed and categorized by a radiologist (SJZ), and consultant otolaryngologists, focusing on 3D microanatomy of the fronto-ethmoidal transition, the frontal recess/frontal sinus, and drainage pathways, in comparison to established anatomical classification systems.

Results: The anterior ethmoid is subdivided into seven groups with the following core properties and prevalence: 1 . The horizontal roof of the IS-EUP is attached to the superior half of the frontal process of the maxilla (19\%); 2 . The IS-EUP extends into the frontal recess (6.5\%); 3. The IS-EUP extends into the frontal recess and the frontal sinus (18.5\%); 4 . A bulla is seen in the medial frontal sinus (3\%); 5 . The ethmoid bulla and supra bullar space extend into the frontal sinus (7\%); 6 . Lamellae extend into the FSRS antero-superiorly (25\%); 7. FSRS expansion expands below the upper half of the frontal process of the maxilla (FSRS) (21\%).

Conclusion: 3-D analysis of the detailed anatomy provides important new anatomic information with the increased focus on precision surgery in the region.

Key words: frontal recess, frontal sinus, frontal sinus drainage pathway, uncinate process, 3D CT stereo $\neg$ scopic imaging

\section{Introduction}

There have been several attempts, over the last 30 years to describe Frontal Recess (FR) anatomy and classify it into a system based on air cells. The intention has been to clarify the frontal sinus drainage pathway and enhance the surgical approach to the frontal sinus. Each of the proposed classification systems begin with the "simplest" pattern, the single agger nasi cell. Furthermore, several types of fronto-ethmoidal / frontal cells, the frontal bulla, supra-bullar cells, the supra-orbital ethmoid cell and the inter-frontal sinus septal cell are listed ${ }^{(1-9)}$. Most of the classifications were based on 2-dimensional CT coronal and multiplanar reconstructed images. As essential as these images are, they do not easily lead to an intuitive 3-D understanding of the frontal sinus drainage pathway's complexity (FSDP). Conversely, 3D CT stereoscopic imaging (3DCTSI) does provide the intuitive display of this regional anatomy, affording additional insight and details, which we feel complement the available practice-oriented classification systems ${ }^{(10,11)}$. 
The objective of this paper is to describe the 3-dimensional patterns of anterior ethmoid pneumatization found in the 200 pathology free ethmoid sinuses of 100 patients examined with 3-DCTSI. The focus is on defining extent, variability and interconnectivity of the three anterior sinus spaces: the Frontal Sinus Recess Space (FSRS); the Infundibular Space of the Ethmoidal Uncinate Process(IS-EUP) and the Ethmoid Bulla Space (EB), as well as their resulting influence on the individual frontal sinus drainage pathway (FSDP) ${ }^{(11)}$. When 3DCTSI are compared with the previously described cellular classification systems, several new concepts emerge. The aim of this presentation is to describe the additional detailed anatomic observations with illustrated examples and prevalence data from the 200 sinuses. All investigations and statements are made with reference to historic literature and currently used definitions referring to e.g. the frontal recess, the frontal sinus drainage pathway and the frontal bulla ${ }^{(12-24)}$.

\section{Materials and methods}

\section{Imaging equipment}

Axial CT scans were performed on a Siemens CT scanner using $0.7 \mathrm{~mm}$ thick slices, which provided a volumetric image data set of the maxillo-facial structures. Studies were performed without administration of intravenous contrast material.

An advanced evolution of the Dextroscope imaging device was used to create 3D CT Stereoscopic Imaging displays (3DCTSI). The device provides an "en bloc" 3D display of the imaging data. The availability of a scrolling removal of the image data in any plane can be employed to display the anatomic information of interest. With a "virtual surgery" capability structures which obstruct the visualization of specific anatomic detail may be removed.

The 3DCTSI created by the Dextroscope imaging device are displayed on a stereoscopic monitor and are viewed with 3D electronic glasses. The stereoscopic display provides depth perception showing a structure, just as it would appear in nature. The display of the 3D stereoscopic image on a "flat" surface presents a challenge, manifested by the 2.5 dimensional images presented in the manuscript.

\section{Source of information}

100 patients ( 200 sides) who had undergone $C T$ of the sinuses over the past seven years, using an image guided protocol, aged 21-75 years old to evaluate the Frontal Sinus Drainage pathway. The cases were selected from a pool of cases reported to have no inflammatory or neoplastic pathology. This was a retrospective study performed on de-identified CT data approved by The Johns Hopkins Medical Institutions IRB.

\section{D stereoscopic imaging evaluation}

Our evaluation includes: the frontal sinus with the frontal recess
Table 1. Key to abbreviations.

\begin{tabular}{|c|c|c|c|}
\hline $\begin{array}{l}\text { Abbre- } \\
\text { viations }\end{array}$ & Definitions & $\begin{array}{l}\text { Abbre- } \\
\text { viations }\end{array}$ & Definitions \\
\hline Lamellae & & Landmarks & \\
\hline $\mathrm{Ba} \mathrm{La}$ & $\begin{array}{l}\text { Basal Lamella Middle } \\
\text { Turbinate }\end{array}$ & FNMS & $\begin{array}{l}\text { Fronto-Nasal Maxil- } \\
\text { lary Suture }\end{array}$ \\
\hline $\mathrm{BL}$ & Bulla Lamella & FPM & $\begin{array}{l}\text { Frontal Process } \\
\text { Maxilla }\end{array}$ \\
\hline $\mathrm{CL}$ & Common Lamella & ITFPM & Inferior tip of FPM \\
\hline UL & Uncinate Lamella & LP & Lamina Papyracea \\
\hline SAUP & $\begin{array}{l}\text { Superior Attachment } \\
\text { of the Uncinate } \\
\text { Process }\end{array}$ & & \\
\hline Spaces & & SKB & Skull Base \\
\hline ANC & Agger Nasi Cell & SNS & $\begin{array}{l}\text { Superior Nasal Spine } \\
\text { (nasal beak) }\end{array}$ \\
\hline EB & Ethmoid Bulla & Miscellane & ous \\
\hline El & $\begin{array}{l}\text { Ethmoidal Infundi- } \\
\text { bulum }\end{array}$ & A & Anterior \\
\hline FR & Frontal Recess & AP & Anterior to Posterior \\
\hline FS & Frontal Sinus & $\mathrm{CT}$ & $\begin{array}{l}\text { Computed X-ray } \\
\text { Tomography }\end{array}$ \\
\hline FSDP & $\begin{array}{l}\text { Frontal Sinus Drai- } \\
\text { nage Pathway }\end{array}$ & $\mathrm{D}$ & Direct \\
\hline FSRS & $\begin{array}{l}\text { Frontal Sinus/Recess } \\
\text { Space }\end{array}$ & I & Indirect \\
\hline ILS & Inter-Lamellar Space & $\mathrm{L}$ & Lateral \\
\hline IS-EUP & $\begin{array}{l}\text { Infundibular Space } \\
\text { of the Ethmoid Unci- } \\
\text { nate Process (ANC) }\end{array}$ & $M$ & Medial \\
\hline MM & Middle Meatus & $M L$ & Medial to Lateral \\
\hline RBR & Retro Bullar Recess & MPR & $\begin{array}{l}\text { CT Multiplanar Recon- } \\
\text { struction }\end{array}$ \\
\hline RBS & Retro-Bullar Space & $\mathrm{P}$ & Posterior \\
\hline SBS & Supra Bulla Space & $\mathrm{S}$ & Superior \\
\hline $\mathrm{TI}$ & $\begin{array}{l}\text { Turbinal Infundibu- } \\
\text { lum }\end{array}$ & 3DCTSI & $\begin{array}{l}\text { 3D CT Stereoscopic } \\
\text { Imaging }\end{array}$ \\
\hline $\mathrm{TR}$ & Terminal Recess & & \\
\hline
\end{tabular}

(FSRS); the bony architecture of the uncinate process and its spatial configuration (IS-EUP); the relationship of these structures to the bulla lamella, and supra-bulla space; and the communicating/drainage passages, the middle meatus, the ethmoid and turbinal infundibulum; as well as the perimeter of these structures and interrelationships. The images were evaluated by SJZ with consultations provided by otolaryngologists (FAK, DK, $A L, N R L, W H)$.

\section{Results}

The study is focused on the 3DCTSI appearance of the anterior ethmoid sinus spaces and the fronto-ethmoidal transition 
Table2. Grouping according to core features and individual variability of microanatomical spaces of the anterior ethmoid.

Core features (groups) and individual variability of microanatomical spaces of the anterior ethmoid.

Group 1. Standard IS-EUP with a singular space at the agger nasi (the "simple ANC"). (38/200 - 19\%).

The horizontal IS-EUP roof / floor of the FSRS adheres to the region of the fronto-nasal / fronto-maxillary suture or the superior $1 / 2$ of the FPM, and extend laterally to the lamina papyracea and posteriorly, to the bulla lamella (BL), without expansion into the FSRS.

Group 2. IS-EUP pneumatizes into the Frontal Recess. (13/200 - 6.5\%).

The roof of the combined spaces of the IS-EUP expands above the fronto-nasal / fronto-maxillary suture, decreasing the height and compressing the FR infero-medially. FR drains medial into MM and El. Subgroups:

A. Two chambered IS-EUP extends into FR (6/200).

B. A TR space extends into FR and drains into El (3/200).

C. Multichambered IS-EUP expands across into FR (4/200).

Group 3. IS-EUP expands into FR and FS (37/200 - 18.5\%).

FR drains medial to MM, posterior/medial to El. Subgroups:

A. IS-EUP roof fuses with posterior FS floor or anterior FS wall (10/200).

B. A single large space pneumatizes into the posterior FS (11/200).

C. A TR extends into anterior FR and posterior FS (16/200).

Group 4. "Frontal Bulla"- a pneumatized Space in the Frontal Sinus (6/200 - 3\%).

A "balloon-like" space in the medial FS, attached by extensions of a combined UL/BL- (4/6) or UL/CL-lamella (2/6). The lamella is "string- like" (3/6) or "shorter and thick" (3/6). The Bulla opens into the FS, IS-EUP, and FR in all sides. FR drains to: MM medial (6/6); El posterior-medial (4/6) or anteriorlateral (2/6). In 1 case a FSRS communicated with the superior nasal meatus through openings in the BL and Ba La of the MT.

Group 5. The Fronto-Bullar Space (14/200 - 7.5\%).

A. Supra Bullar Recess Space expands into Frontal Sinus (11/14).

B. Supra Bullar Recess Space (SBS) and Frontoethmoidal Space (Group 3) both expand into frontal sinus (3/14).

The FS is enlarged and may be associated with supraorbital ethmoid spaces. The anterior extension of the SBS may be mistaken for a frontal bulla (Group 4).

Group 6. “Compression / reduction” of the FSRS by antero-superiorly expanding lamellae (50/200 - 25\%).

FSRS drains medial into MM \& El. Subgroups:

A. The "contracted/diminished" Frontal Recess altered by the Bulla Lamella. (22/50), expanding in majority of the FR (14/22) or all of FR (8/22). TR present in (4/12).

B. The "contracted/diminished" Frontal Recess altered by the Uncinate Lamella (17/50), expanding in majority of the FR (8/17) or all of FR (9/17).

TR present (4/17) and ILS present (13/17).

C. The "contracted/diminished" Frontal Recess altered by the Common Lamella (11/50), expanding in majority of the FR (3/11) or all of FR (8/11).

TR present (5/11) and ILS present (6/11).

Group 7. The pronounced inferior/anterior/medial/lateral expanding FSRS. (42/200 - 21\%). The IS-EUP is displaced inferiorly, laterally, or posteriorly. Subgroups:

A.1 The inferior/postero-lateral expanding FSRS (12/42). The IS-EUP is "pushed" medially (7/12), or posteriorly (5/12). The

FSRS inferior level is at: inf. $1 / 2$ of FPM (10/12); sup 1/2 of FPM (2/12). Drainage to MM, is medial; into El posterior-medial (10/12), or lateral (2/12).

A.2 The inferior-anterior and lateral-medial expanding FSRS (18/42). The openings in the roof are superior-lateral (9/18); posterior-lateral (5/18) or

the entire roof (4/18). Drainage to MM is medial (18/18); to El lateral (8/18) or lateral and medial (10/18).

B. The inferior expanding FSRS through opening or intact roof of IS-EUP (12/42).

region, i.e. the Frontal Sinus Drainage Pathway (FSDP). Table 1 provides the abbreviations and their definition used throughout the manuscript. The individual location, extension, shape and interrelation of the specific spaces (e.g. IS-EUP, EBS, FR, FSRS) as well as their influence on the spatial arrangement of the frontal sinus drainage pathway (FSDP) were systematically analyzed (Table 2). Detailed anatomical groups were defined, which are characterized by structural commonality. Seven groups were identified, which are listed with their prevalence in Table 2 and illustrated in Figures 1-7.

\section{Discussion}

A preoperative intimate understanding of the anatomy, and especially the frontal sinus drainage pathway is essential for minimally traumatic surgery, particularly in minimally invasive and balloon procedures. Novel diagnostic technology as well as surgical techniques continue to evolve adding to the anatomical knowledge and the descriptive terminology, however, as Lund et al. state "give scant consideration to the detailed sinonasal anatomy, and lack a uniformity in terminology and definitions" (8). Attempts to clarify the anatomy of the paranasal sinuses, its description and definitions was attempted by Stammberger and Kennedy, with a panel of international experts in $1991^{(13)}$, followed by the "Terminologia Anatomica" publication in 2011 (14), and in 2014 the European Position Paper on the Anatomical Terminology of the Internal Nose and Paranasal Sinuses (8). Furthermore, the description of the anterior ethmoid sinus anatomy and its relationship to the FSDP has been addressed by several classifications, the primary ones are above described ${ }^{(1-9)}$. Our aim is to augment the previous observations with those provided by 3DCTSI. 


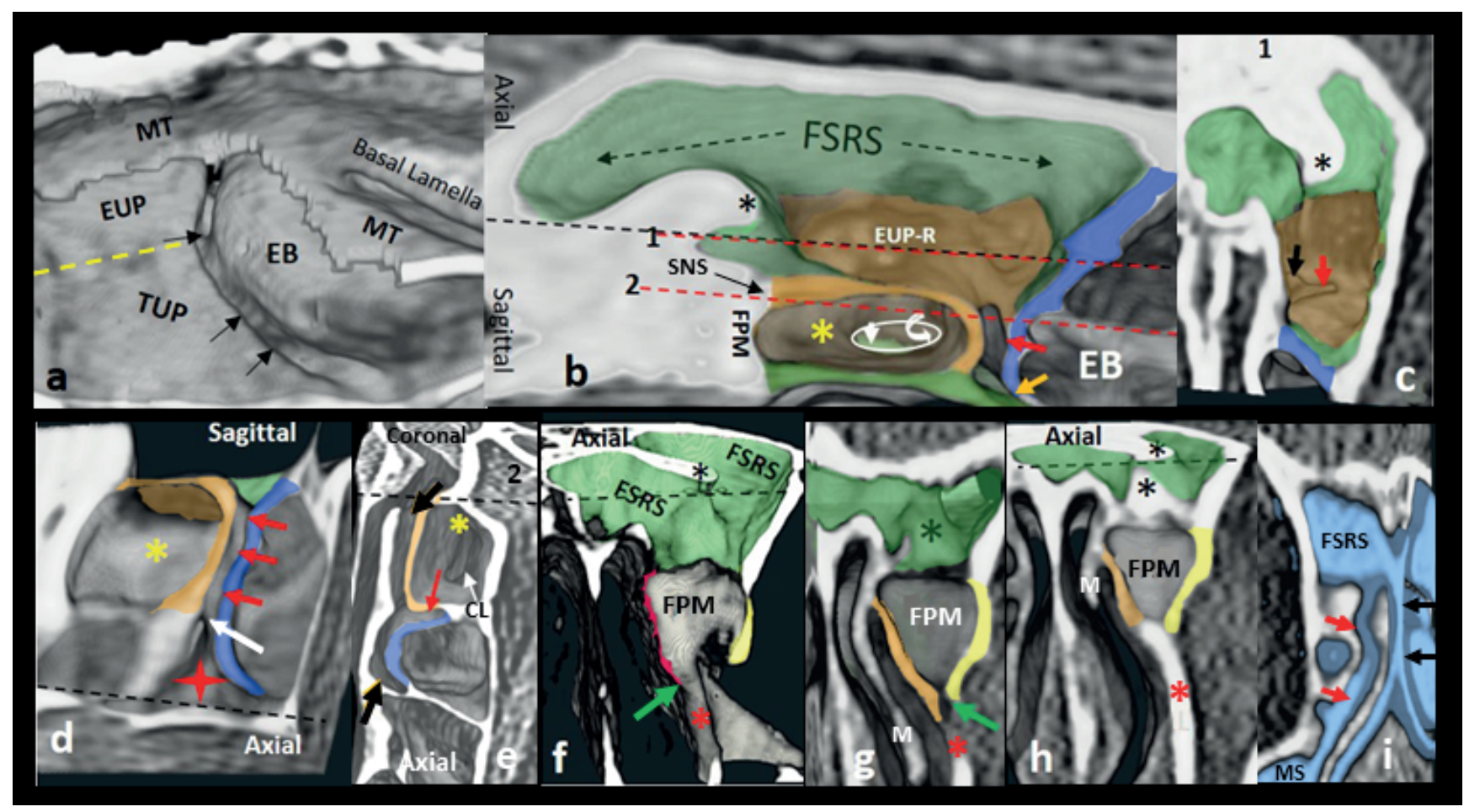

Figure 1. Standard IS-EUP with a singular space at the agger nasi (the "simple ANC").

a. 3D obliqued sagittal image of the right anterior ethmoid viewed from medially, status post subtotal middle turbinectomy (remnants: MT).

Demonstration of the two segments of the Uncinate Process (EUP, TUP; plane of separation: yellow dashed line). Black arrows: hiatus semilunaris. b. 3D medial obliqued axial plane above, and sagittal below black dashed line. The roof of the IS-EUP (gold outline) is the floor of the FR (IS-EUP-R), and extends from anteriorly at the SNS, posteriorly to the bulla lamella (blue outline), and laterally to the lamina papyracea (LP). Note the opening in the base of the anterior-superior "cavity" of the IS-EUP, formally known as agger nasi cell (white oval), and it's with the posterior TI (curved white arrow, gold arrow), as well as the communication with the TI (white arrow). Red arrow: ethmoid infundibulum; gold arrow: turbinal Infundibulum; light green outline: FSRS; dark green outline: TUP; red dashed line 1: plane of axial image, fig. c; red dashed line 2: plane of axial image, fig. e.

c. 3D axial view from above displays the FSRS floor (FS-light green, and FR-gold outlines). The border between the green and gold outlines represents the separation between FS and FR. Note the direct opening into the MM (black arrow), and the direct opening into the El (red arrow).

d. 3D obliqued sagittal plane, showing the direct communication of the FSRS with the superior El (red arrows). Note communication of the anteriorsuperior "cavity" of the IS-EUP (yellow asterisk) with the postero-superior TI (white arrow). Red star: TI.

e. 3D axial view from above shows the IS-EUP (yellow asterisk), its relationship with the Bulla Lamella (blue outline), the Common Lamella (CL), and the Middle Meatus (black arrows).

f.-h. Obliqued 3D coronal/axial images viewed from posteriorly show the "posterior surface" of the Frontal Process of the Maxilla (FPM), with a bony ridge (black asterisk) creating two inferior segments in the FS (green outline). Note site of attachment to the medial FPM by the Uncinate Lamella (gold outline), the lateral attachment by the Lamina Papyracea (yellow outline) the horizontal plane of the Fronto-Nasal-Maxillary Suture/SNS (red asterisk); antero-inferior site of fusion by UL/LP/Lacrimal bone (red asterisk) (green arrow); Middle Turbinate (M).

i. 3D obliqued coronal/sagittal view shows the air spaces (blue outlines) within the anterior ethmoid sinus, the FSRS, and the draining channels: the Ethmoid Infundibulum (red arrows); and the Middle Meatus (black arrows), both directly communicating with the FSRS. Maxillary Sinus (MS).

From the start of our evaluation, we were faced with the issue: Is the construct of the FS/FR, and anterior Ethmoid Sinuses assembled by "cells" or "spaces"?

Conventional terminology ${ }^{(12-24)}$ has long referred to the ethmoid sinuses as being a collection of individual air cells and the planar 2-dimensional CT images have cemented this concept in our minds, as a given fact ${ }^{(25-45)}$. Van Alyea, in his summary of the manuscript on "Frontal Cells" states "considerable confusion exists concerning the classification of minor cells in the frontal area, and that the term "frontal cells" is regarded as a fitting title for these cavities, and should not be confused with the major cavity of the frontal bone, the frontal sinus". Here Van Alyea shows his ambivalence regarding which term to use "cell vs. space" (20,21). However, in this case, Dorland's Medical Dictionary provides clarity in that "a cavity is a space within the body or in one of its organs" (22). Terrier et al. described the structure of the paranasal sinuses to be the result of a centrifugal pneumatization giving shape to spaces with openings into common pathways for 


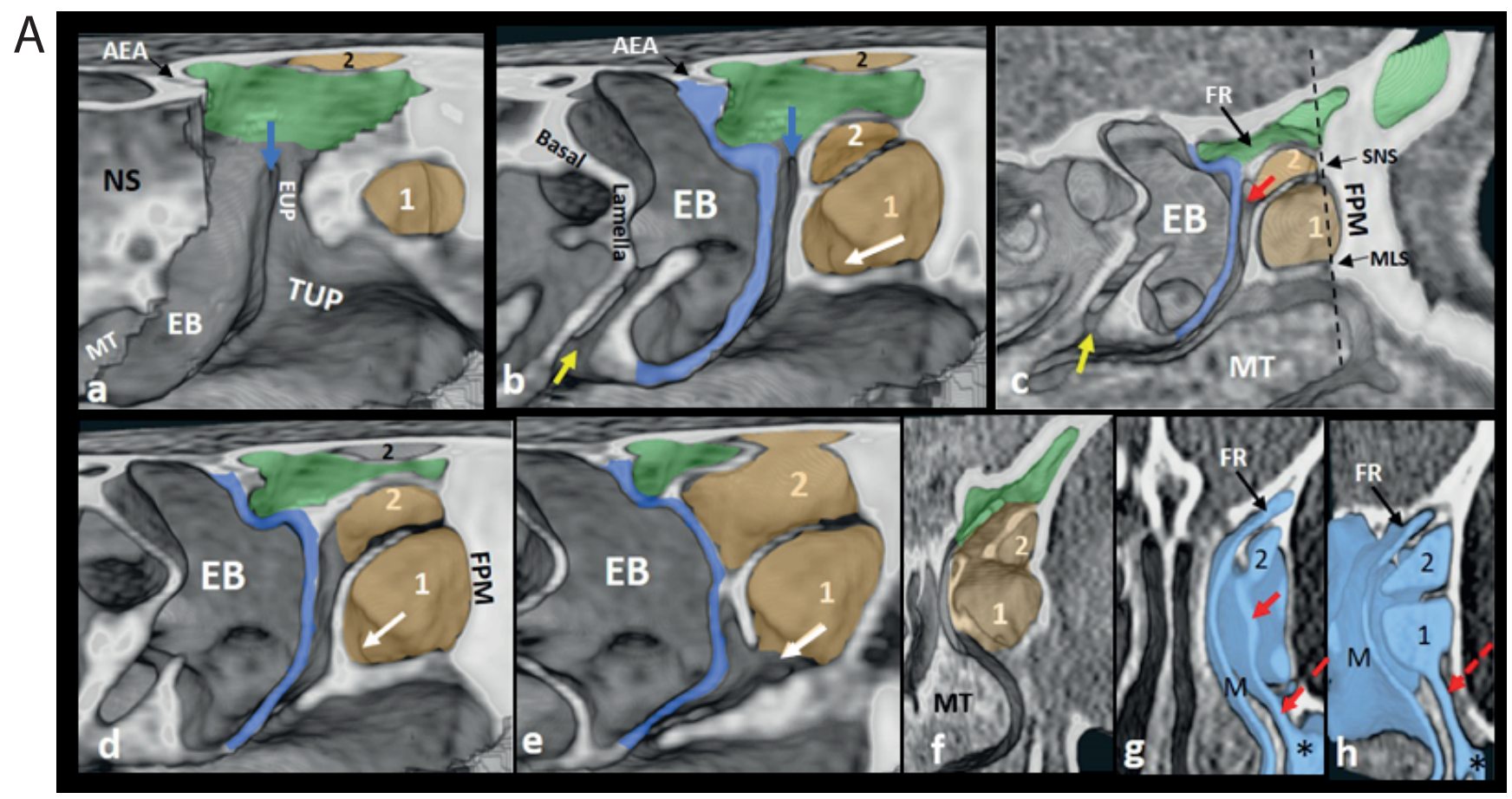

Figure 2. IS-EUP pneumatizes into the Frontal Recess.

A. Two chambered IS-EUP expands into Frontal Recess.

a.-e. 3D slight medial obliqued sagittal images (left side, sequentially from medial to lateral) status/post an irregular virtual resection of the anterior middle turbinate reveals the FSRS (light green), and the IS-EUP includes two compartments (gold outline, 1,2). Note the communication of the FSRS with the Hiatus Semilunaris (blue arrows). The superior IS-EUP compartment (2) extends supero-laterally to fuse with the LP, and narrowing the medial FR space, and has an individual drainage into the El (red arrow). The inferior IS-EUP compartment (1) drains infero-posteriorly into the TI (white arrows). Note the oblique vertical dashed line in Fig. c, a plane adhering to the SNS superiorly, and the Maxillo-Lacrimal Suture inferiorly, a proposed plane of virtual separation between the FS and FR. TUP: Turbinal Uncinate Process; yellow arrow: Retro Bullar Recess Space.

f. 3D obliqued coronal view from anteriorly reveals the FSRS (green outline), and its relationship with the two compartments in the IS-EUP (gold outline, 1,2), enclosed within the bony outline of the EUP. MT: Middle Turbinate.

g., h. 3D obliqued coronal images viewed from anteriorly, show the 3D air outline within the Frontal Recess (FR), and its communication with the Middle Meatus (M), and that compartment \#1 drains into the El (red arrow) and subsequently into the TI and maxillary sinus (black asterisk). The inferior compartment \#2 drains into the TI (dashed red arrow), and into the Maxillary Sinus.

Larger red arrow: points to the TI which inferiorly then communicates with the maxillary sinus (hidden in these images).

mucus clearance and exchange of air ${ }^{(42)}$. Pianta et al. referred to air spaces within their ABC classification, not cells ${ }^{\left({ }^{44}\right)}$. Arun et al. described the Frontal Recess as a "three-dimensional space connecting the Frontal Sinus with the nasal cavity" (27). Thomas and Pallanch in their 3D CT reconstructions and virtual endoscopy of the frontal recess, reported explicit difficulties in subdividing the actual spaces of the anterior ethmoid into cells, blind pockets, recesses and segments of the frontal sinus drainage pathway ${ }^{(45)}$. However, 3DCTSI demonstrates an alternative explanation, that the Ethmoid Sinuses are in fact a collection of inter-related air spaces which are connected by well-defined draining passages. The three inter-related spaces are: the combined FS and FR spaces (FSRS); the Infundibular Space of the Ethmoid Uncinate Process (IS-EUP), The Turbinal Infundibulum (TI); and the Ethmoid Bulla Space which includes the Supra Bullar Space (SBS).
The Infundibular Space of the Ethmoid Uncinate Process (ISEUP), previously the Agger Nasi Cell, and the Infundibular Space of the Turbinal Uncinate Process (TI).

The Uncinate Process, as previously detailed (11), and shown in Figure 1, blends into the ethmoidal construct with a spatial configuration having two segments: the Turbinal Uncinate Process (TUP), which extends in a sagittal plane from the lacrimal bone, anteriorly, to visually terminate at the posterior fontanelle, creating a vertically oriented space with the medial maxillary sinus, the Turbinal Infundibulum (TI); and the Ethmoidal Uncinate Process (EUP, UL) which extends from antero-medially, along the medial border of the frontal process of maxilla (FPM), adhering supero-laterally to the fronto-nasal maxillary suture (FNMS), reaching the lamina papyracea (LP), then extending in a horizontal or supero-lateral plane as it remains fused to the LP, 


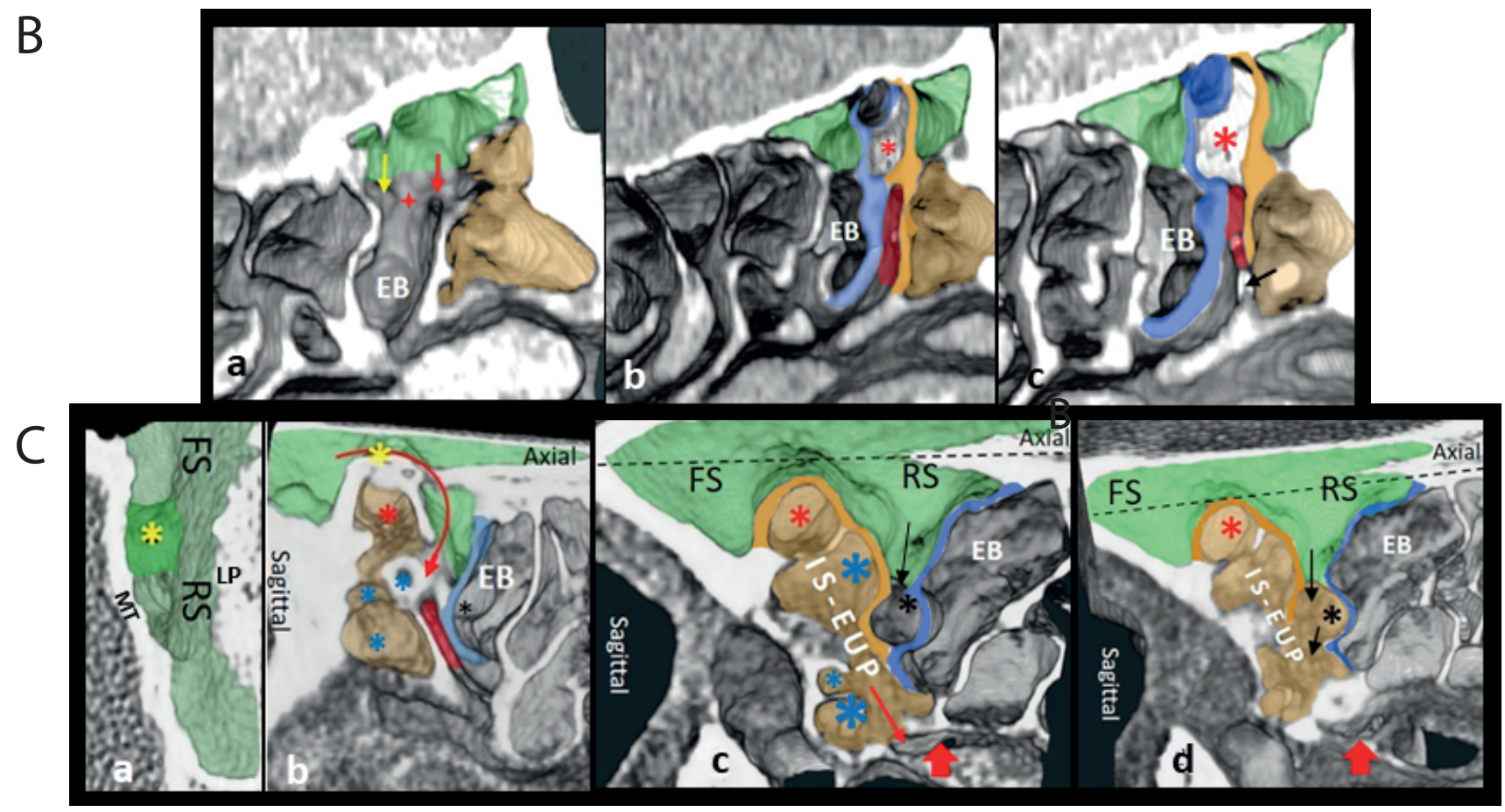

Figure 2. IS-EUP pneumatizes into the Frontal Recess.

B. "Terminal Recess" space pneumatizes into the Frontal Recess.

a.-c. Sequential 3D sagittal images (left side from medial to lateral reveal the wide medial communication of the FSRS (green outline) with the Middle Meatus (red +) and the direct communication with the hiatus semilunaris (red arrow), and the Retro Bullar Recess posteriorly (yellow arrow). Note in Figs. $b$ and $c$, the appearance of an infundibular space within the frontal recess created by the merging of the superior outlines of the Bulla Lamella posteriorly (blue outline), and the uncinate lamella anteriorly (gold outline), creating a "terminal recess space" within the frontal recess which directly communicates with the EI (red outline). The inferior IS-EUP space communicates directly with the TI (black arrow). Gold outline: IS-EUP; Terminal Recess Space in Figs. b and c (red asterisk).

C. Multichambered IS-EUP expands across into the Frontal Recess.

a. 3D axial image viewed from above shows the inferior FSRS (green outline, right side), with a focal bulge raising the floor of the FSRS (yellow asterisk), representing the superiorly expanding EUP, from the Middle Turbinate (MT) to the Lamina Papyracea (LP) laterally.

b.-d. 3D sagittal images viewed sequentially from medial to lateral reveal the multi chambered IS-EUP (IS-EUP, red and blue asterisks). The superior chamber (red asterisk) has an individual direct drainage into the MM and indirect drainage into the El (red outline) (Fig. b). The FSRS (green outline) drains posteriorly and medially into the MM (curved red arrow) (Fig. b). The images also show the appearance of an infundibular space (Figs. $\mathrm{c}$ and d) (black asterisk) created by the convergence of the Bulla Lamella (blue outline), posteriorly and the uncinate lamella anteriorly (brighter gold outline). This space has a supero- lateral opening affording communication with the FSRS, and infero- medially opens into the IS-EUP (black arrows). Larger red arrow: points to the TI which inferiorly then communicates with the maxillary sinus (hidden in these images).

to posteriorly fuse, in the majority of cases, to the bulla lamella (BL). In its fusion with the mentioned anatomy the UL creates a 3-dimensional polyhedral space which communicates with the inferior El and the TI (Figures 1-7), therefore creating two infundibular spaces: the IS-EUP, and the TI.

It is not our intention to change previously held beliefs, but to clarify previously held beliefs which do not adhere with the actual anatomic configuration(s) present. "Point in view" is the use of the term Agger Nasi Cell (ANC), which has a surgical inference i.e., the space lateral to the "mound" in the lateral nasal wall. The relationship between the ANC and the UP was first addressed by Zuckerkandl (1892) who described "the UP to form a "body" with the agger nasi, the free part of which is the agger, and the covered part is the uncinate process" ${ }^{\prime(16)}$. Lang, similarly states: "the processus uncinatus represents the immediate continuation of the agger nasi and shows numerous variations of its setting, width, thickness, as well as connections with neighboring bones" (24). In fact however, the "cell" is a polyhedral space, with borders above described, as well as an opening to the TI, therefore, is an infundibular space i.e., the IS-EUP (Figures 1-7). That said, one should consider the "ANC" to be a compartment within the IS-EUP. 
A

B
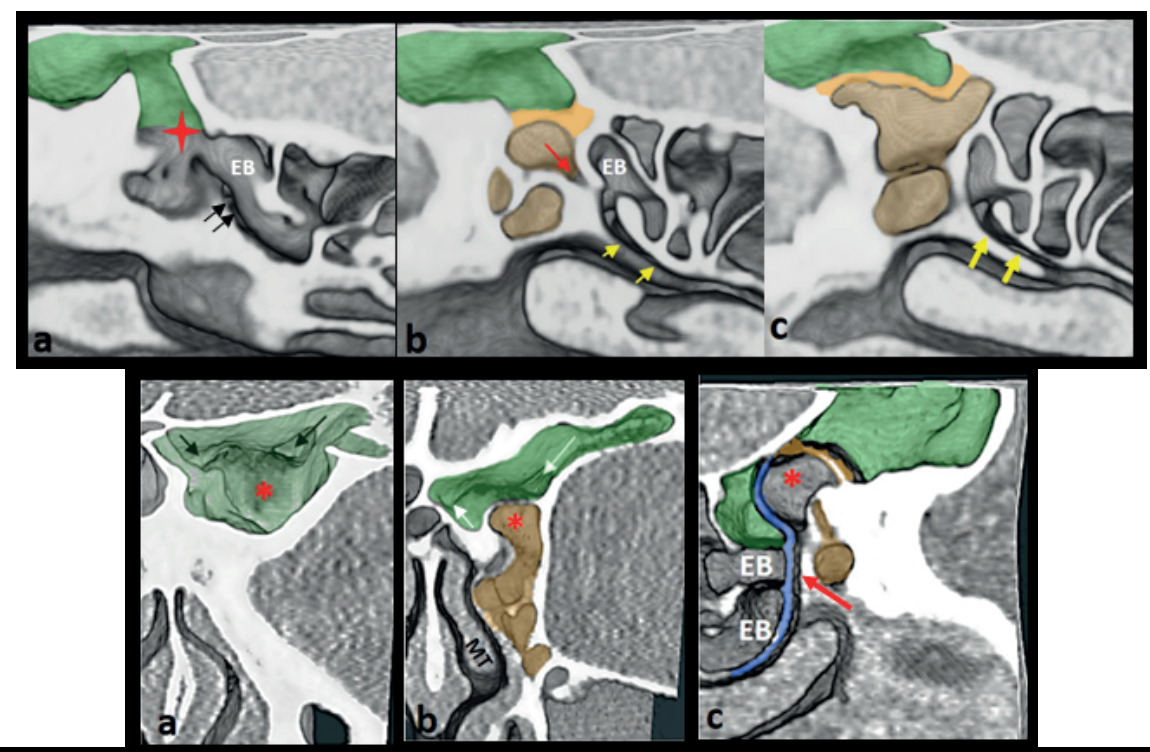

C

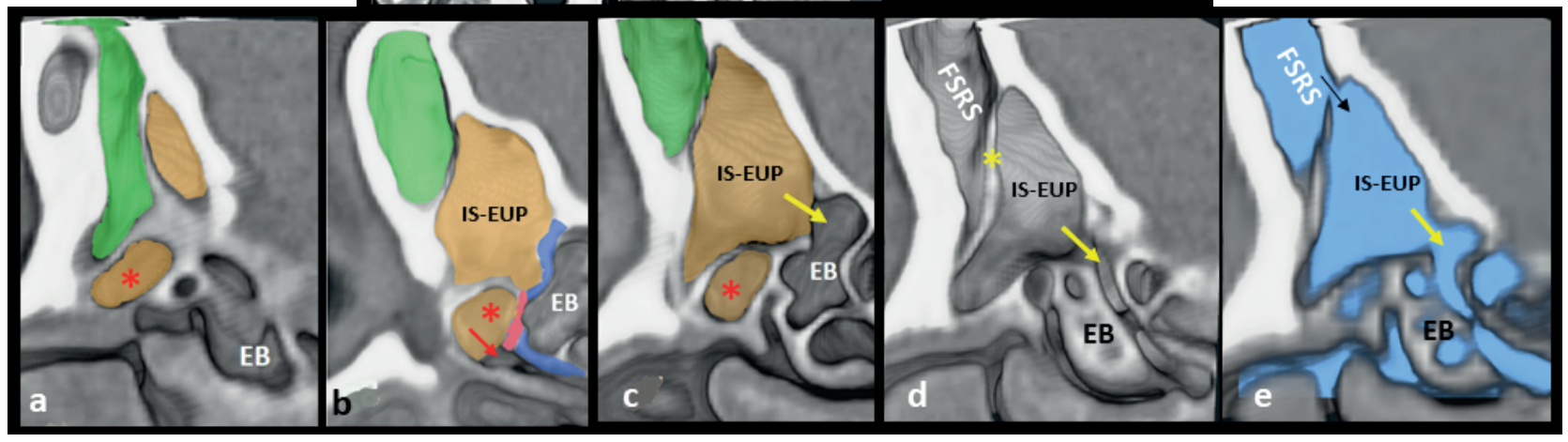

Figure 3. Expansion of IS-EUP into FR \& FS.

A. IS-EUP expands into the FSRS fusing to the posterior floor, and anterior wall of FS.

a.-c. 3D sagittal images viewed progressively from medially to laterally. The roof of the EUP/floor of the FSR adheres (gold outline) to the posterior floor of the FS (green outline), and the anterior FS. Note in Fig. a, the direct communication of the FSRS with the Middle Meatus (red star), and indirectly with the El (black arrows), and directly with the TI (red arrow, yellow arrows).

B. A Terminal Recess space expands into the FR \& FS.

a, b. 3D coronal image viewed from anteriorly reveal the FSRS (green outline), with a central bulge narrowing its height (red asterisk). Note openings superomedial and lateral (black and white arrows) between the "bulge" and the roof of the FSRS, affording communication with the posterior FSRS. c. 3D sagittal image reveals that the superiorly expanding space into the FSRS, is a "Terminal Recess" created by the superior merge between the uncinate lamella (gold outline) and the Bulla Lamella (blue outline), and that this space communicates directly with the El (red arrow).

C. A single large space within the IS-EUP expands into FR \& posterior FS.

a.-c. 3D sagittal images (right side) reveal the inferior extension and narrowing of the FSRS (green outline), and the superior extension of larger compartment within the IS-EUP (gold outline) to skull base. Note site of communication between IS-EUP and Supra Bulla Space in fig. c. d. and e. 3D sagittal image showing the anterior outline of the superiorly extending Uncinate Lamella (yellow asterisk) to skull base as well as the posterior communication between the IS-EUP and the RBS (yellow arrow). Fig. e, is similar to fig. d, with 3D blue outline of the air spaces in the FSRS and IS-EUP as well as EUP 3dimensionality of the air spaces within the FSRS with their superior communication (black arrow) and the posterior communication between the IS-EUP and the RBRS (yellow arrow).

3DCTSI shows the diversity of configurations, compartments, volumes, and effects on the FSRS, the IS-EUP, EB, as well as the FSDP, as demonstrated throughout (Figures 1-7).

Group 1. Unicellular pneumatization of the IS-EUP (previously the "simple ANC"). Its roof, also the floor of the FR, is in the ho- rizontal plane extending from the FNMS, anteriorly, extending along the LP to the BL posteriorly. The roof level may extend inferiorly along the superior $1 / 2$ of the FPM, and does not expand into the FSRS. Drainage from the IS-EUP, is direct into the inferior $\mathrm{El}$, and the $\mathrm{TI}$ (Figure 1). 


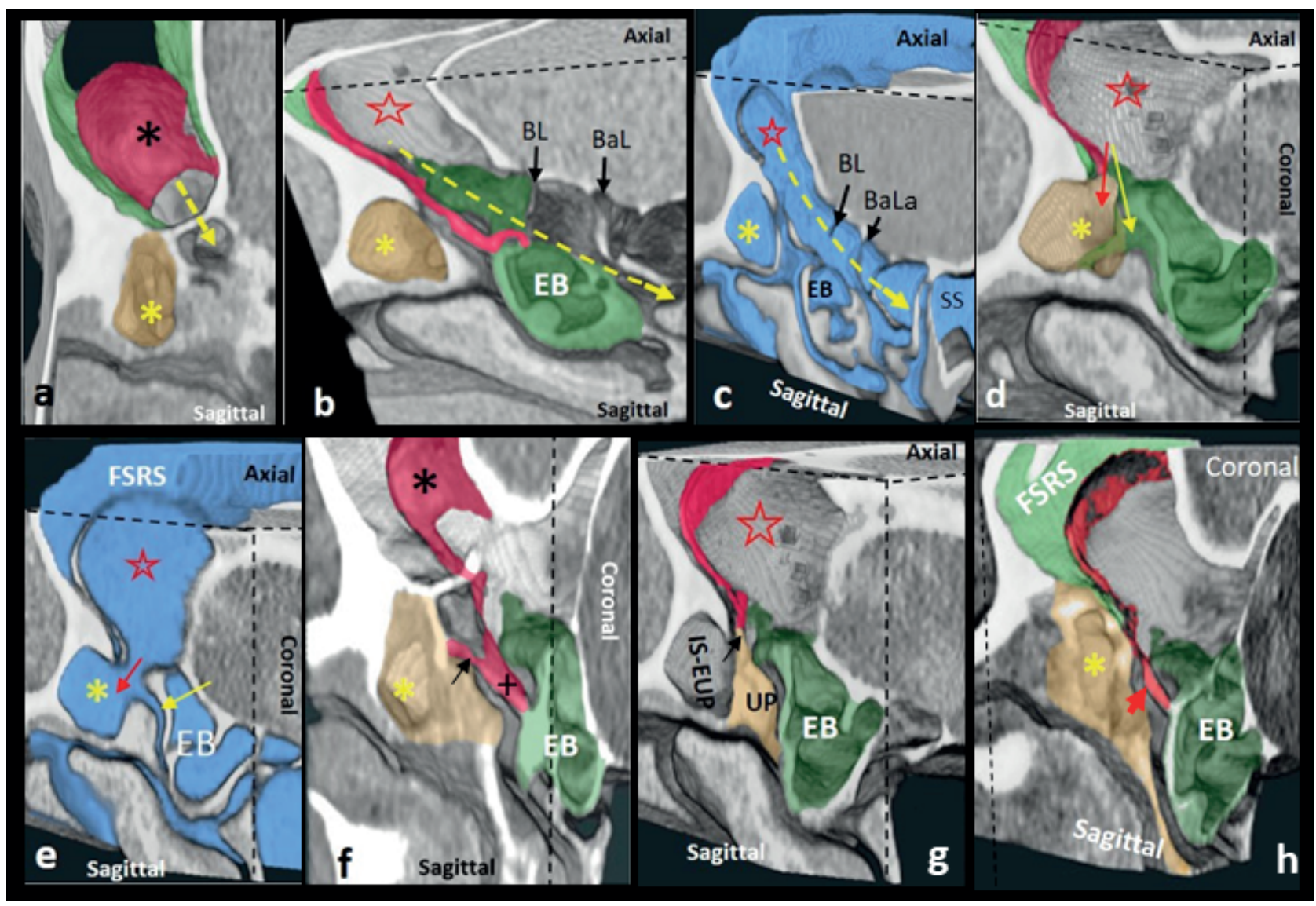

Figure 4. "Frontal Bulla"- a pneumatized Space in the Frontal Sinus.

a. 3D obliqued sagittal image (right side) reveals a "bullous" expansion medially (black asterisk, red outline) and expanding laterally, within the FSRS (light green outline). The "bulla" has a solid attachment to the anterior wall of the FS, and a "feathery" attachment to the posterior wall of the FS. An opening is present within the medial "bulla" (yellow dashed arrow), revealing a direct communication between the Frontal Bulla and the FSR, and the antero-superior ethmoid sinus. IS-EUP (gold outline, yellow asterisk).

b.-e. A variety of 3D obliqued sagittal images, revealing in fig. b a "string like" lamellar attachment (red outline) between the "bulla" in the FS and the Ethmoid Bulla (dark green, EB). Note that the Ethmoid Bulla extends forward into the FR and posterior FS, and that there is a gap in the Bulla Lamella (BL, black arrow) affording communication from FS and "bulla" through the FR into the superior meatus as there is also a gap in the Basal Lamella (Ba La) (dashed yellow arrow). Findings are confirmed in fig. $\mathrm{c}$ with the 3D display of air (blue outline) within the FS, "bulla", anterior and posterior ethmoid sinuses. Gold outline, yellow asterisk: IS-EUP; red star: "bulla" space; SS: Sphenoid Sinus.

d.-e. Communication between the frontal "bulla" space (red star) with the IS-EUP (yellow asterisk) (red arrow) as well as the El (yellow arrow).

f.-h. 3D sagittal images at various obliquities revealing the anteriorly "string shaped" lamella emerging from the EB with a proximal " $v$ " shaped configuration (+) (Fig. f) with its medial "branch" (black arrow) in figs. $\mathrm{f}$ and $\mathrm{g}$, fusing with the uncinate lamella (gold outline), and the "lateral branch" is shown arising from the EB (red arrow) (Fig. h).

Group 2. The IS-EUP space may have 2 or more compartments, which expand into the FR (previously "type 1 \& 2 K cells"; Wormald, single or group of cells above ANC). The compartments are within the outline of the UL and may extend to skull base. In this group we also include a TR space, created by superiorly merging $\mathrm{UL}$ with $\mathrm{BL}$, draining into the $\mathrm{El}$ (an infundibular space). Drainage of the IS-EUP is direct into the inferior El, and TI (Figure $2 \mathrm{~A}-\mathrm{C})$.

Group 3. The IS-EUP expands into the FR and FS (previously "type $3 \mathrm{~K}$ cell"; Wormald, Fronto-Ethmoidal cells extending into $<50 \%$ of the FS vertical height). Three subgroups are identified (Figure $3 \mathrm{~A}-\mathrm{C}$ ): A. The IS-EUP roof expands through the FR to fuse with the posterior floor and/or the anterior and/or posterior FS wall. B. A large superior compartment within the IS-EUP space pneumatizes into the posterior FS. C. A TR space extends into the anterior FR and posterior FS. Drainage of the IS-EUP is direct into the inferior El, and TI. In cases where a large superior compartment extends to skull base, drainage may also be into the SBS or into RBR. 


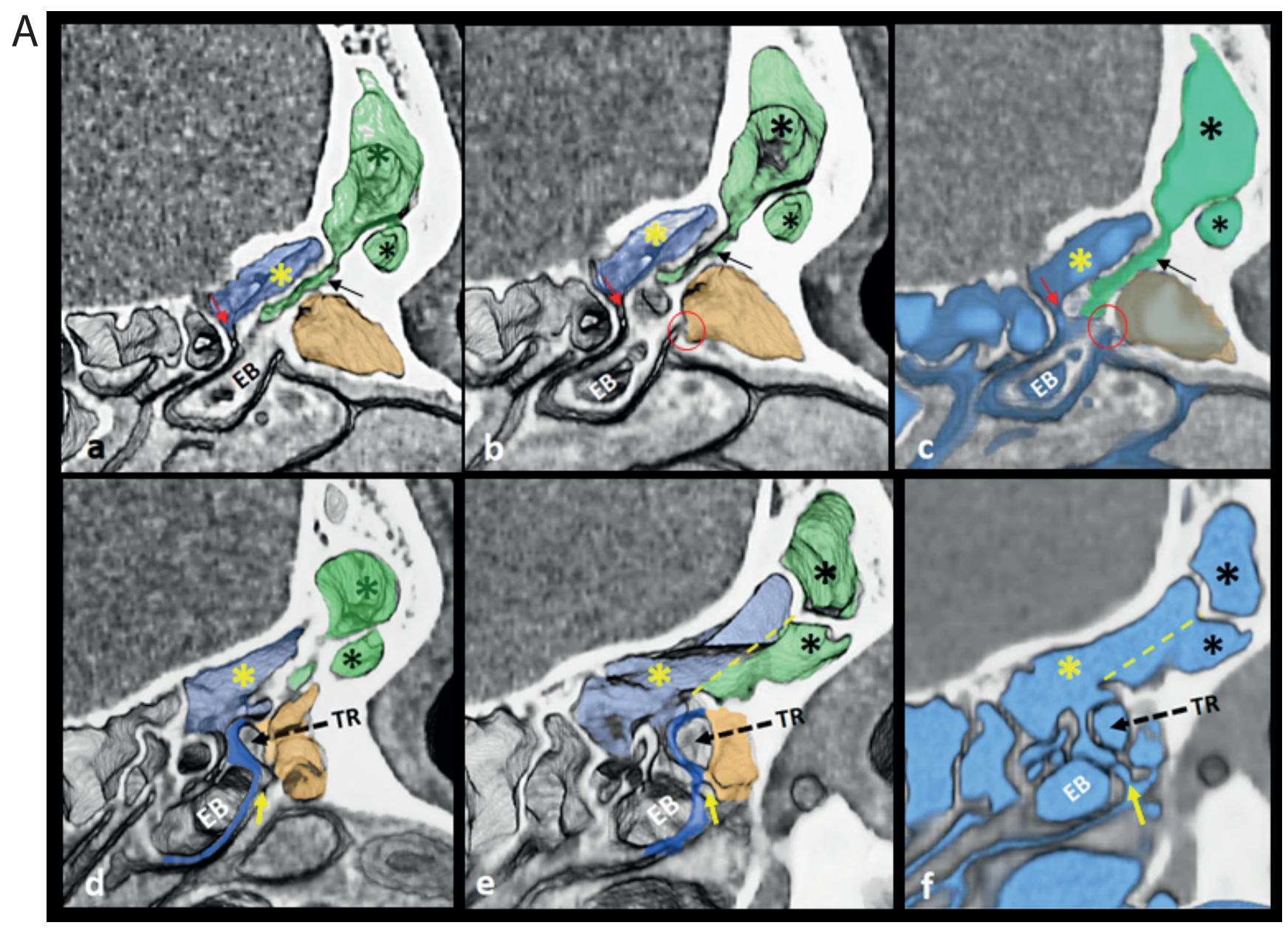

Figure 5. The Fronto-Bullar Space.

A. The Supra Bullar Recess Space expands into Frontal Sinus.

a.-f. 3D sagittal images (left side) in sequence from medial to lateral, reveal the SBS (yellow asterisk, light blue outline) as it extends supero-anteriorly along the skull base, medially, into the space of the FR, with only a narrow space remaining between the IS-EUP (gold outline) inferiorly, and the SBS superiorly (black arrow). Figs. b and c, show the communication between the IS-EUP (gold outline) and the TI (red circle). The posterior SBS communicates with the RBS (red arrow). Laterally, shown in Figs. d.-f., the SBS is in direct communication with the laterally expanding FS (black asterisks). The plane where the SBS and FSRS merge, is shown by the dashed yellow line. Fig. f. reveals the 3D outline of the airspaces within the anterior ethmoid sinus and the FSRS (dark blue outline). Note, note, the creation of a TRS (TR) between the superior UL (gold outline) and the BL (blue outline), which drains into the El (yellow arrows).

Group 4. The "Frontal Bulla" Space (previously "type 4 K cell"; Wormald, Fronto-Ethmoidal cells extending into $>50 \%$ FS vertical height). Van Alyea called the extension of the ethmoid cell into the FS the "Frontal Bulla" (20,21). Bent et al. described it as "a solitary "cell" within the FS" (3) . Later, Lee et al. described it as an anterior ethmoid expansion into the $\mathrm{FS}^{(4)}$, and in 2005 DelGaudio et al. described it as "completely contained in the FS without connection to the FR", and that "'because frontal cells are ethmoid cells that expand through the frontal isthmus, the superior expansion may result in widening of the frontal isthmus, losing its connection to the frontal recess, resulting in a cell completely contained within the frontal sinus" (5). In 2020 Altunay and Onerci reported communication with "the anterior and posterior cell systems" (9). 3DCTSI reveals that the "Frontal Bulla Space" is a "balloon like" space within the FS attached by a "string like" or "thicker lamella" to the UL/BL or UL/CL. Opening(s) in the contour of the bulla, afford communication with the FSRS, IS-EUP, and in one instance given openings in the $\mathrm{BL}$, and Basal Lamella the communication extends to the Superior Meatus (Figure 4).

Note is to be made not to confuse this entity with a Fronto Bullar Space extension into the FS, especially if this latter entity is accompanied by a Fronto-Ethmoidal Space (Figure 5 B).

Group 5. The Fronto-Bullar Space (previously Kuhn, Frontal Bulla, and Suprabullar cells; Wormald, Supra bulla cell and Supra bulla 


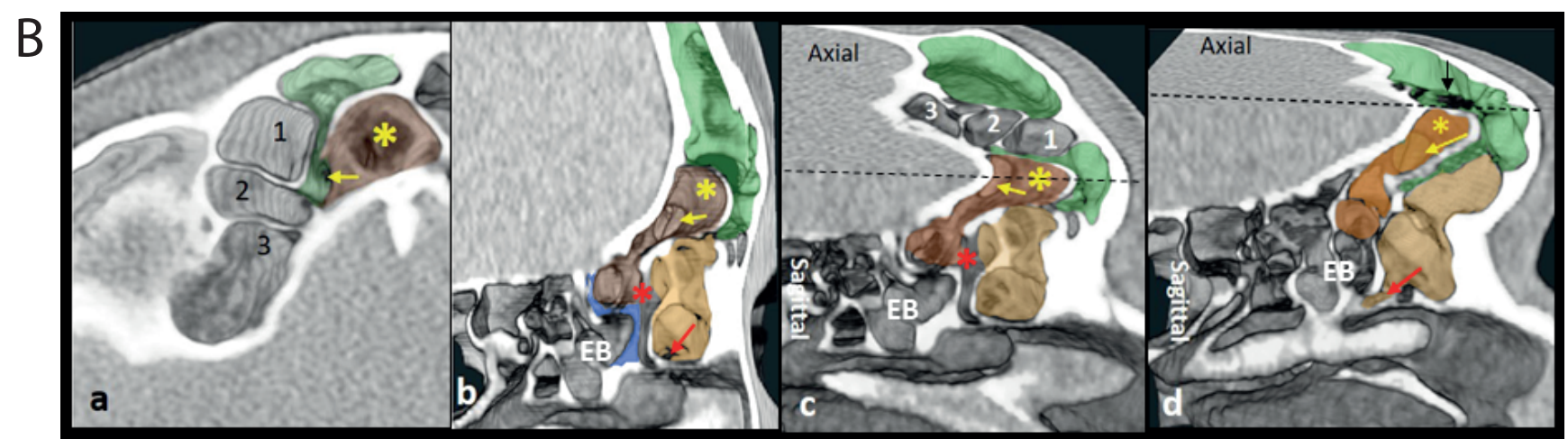

Figure 5. B. Supra Bullar Recess Space and Frontoethmoidal space expand into Frontal Sinus.

a.-d. 3D axial image Fig. a., 3D sagittal image Fig. b., and 3D obliqued images (left side) (Figs. c.-d.), reveal a fronto-bullar space (brown outline/yellow asterisk) expanding into the frontal sinus. The fronto-bullar space originates from the supra-bullar space, and noted to "balloon" anteriorly within the frontal sinus, similar to a "Frontal Bulla" space (Fig. 4). A second commonality with the "Frontal Bulla" is its lateral opening which communicates with the frontal sinus (yellow arrow). The fronto-bullar space communicates directly with the middle meatus, as does the supero-posterior compartment of the IS-EUP (red asterisk). The inferior IS-EUP communicates directly with the TI (red arrow). Note that the supra-orbital frontal spaces (1,2,3) (black arrow), communicate with the EB spaces.

frontal cell). The nomenclature remains unchanged from the previous classifications. 3DCTSI identifies two subgroups: A. The SBRS expands into the FR and FS; and B. The antero-superiorly expanding SBRS is coupled with an IS-EUP space extending antero-inferiorly into the FS paralleling the expansion of the SBRS. In the latter case one needs to be careful not to confuse the SBRS expansion with a Frontal Bulla expansion (Figure $5 \mathrm{~A}, \mathrm{~B}$ ). Note is to be made that The Fronto-Bullar Space, as previously described is the expansion of the Supra-Bullar Space anterosuperiorly into the FS, whereas the "Frontal Bulla" is a "balloon" like space within the FS attached by lamellae arising from the UL and $\mathrm{BL}$ as described above in the description of group 4.

Group 6. "Compression / reduction" of the FSRS by antero-superiorly expanding lamellae. The following is Hajek's, reference to this entity: "The nasal opening of the FS is formed from parts of the ethmoid bone, that is, from the EB or its 'ground lamellas' and the UP. The anteriorly extended 'ground lamellas' diminish the nasal portion of the FS ${ }^{(23)}$. 3DCTSI reveals that in a number of instances, the Bulla, Uncinate, and the Common Lamellae extend antero-superiorly into the FR and/or FS, adhering to skull base (Figure 6 A-C), creating Terminal Recess (TR) and/or InterLamellar Spaces (ILS) within the FSRS.

Van Alyea first referred to the TR with the description "blind ending infundibulum" (21). Stammberger described the superolateral fusion of the uncinate lamella to the FPM and LP as a "blindly ending infundibulum" later referred to as a Terminal Recess ${ }^{(12,13)}$.

The 3DCTSI reveals, that in certain cases, the superior Uncinate Lamella and the superior Bulla Lamella, fuse to create a superiorly enclosed space (Terminal Recess) of various shapes and sizes, within the FR and FS as well as within the anterior ethmoid anatomy, and that the created space is drained by the El (Figures 2 B, 3 B, 4 B, 7B).

The Inter Lamellar Space (ILS), is a space is medially bordered by the MT, antero-laterally by the UL, posteriorly by the BL and superiorly by the superior Middle Turbinate (MT) as it fuses with the skull base. Less commonly it may span, medially, between the BL and the Basal Lamella of the MT. In all cases the space drains into the MM, distinguishing it from the TR which drains into the El. The ILS should not be confused with Grunwald's "interlamellar cell" (18), which was described by Stammberger to be a concha bullosa ${ }^{(12)}$ (Figures 6 C, 7 A, C).

Group 7. The pronounced antero-posterior/lateral to medial inferior expansion of the FSRS bellow the upper $1 / 2$ level of the FPM. The issue in this group is Hajak's statement from group 6, in reverse i.e. "the posterior recession of the ground lamella of the bulla, will expand the FS well posteriorly and inferiorly" (23).

\section{A. 1. The FSRS expands inferiorly, Ant. to Post/Lat. to Med, in} which case the IS-EUP is "pushed" medially, and or posteriorly. In cases where there is a "medial push", an opening is present in the lateral wall of the IS-EUP affording direct communication between the FSRS and the IS-EUP (Figure 7 A 1).

A. 2. The FSRS may expand inferiorly and in-between the FPM and the IS-EUP, the latter is "pushed" posteriorly (Figure 7 A 2).

$B$. The FSRS expands inferiorly through an opening in the roof of the IS-EUP (Figure 7 B).

C. The FSRS Expands inferiorly without invading the IS-EUP roof. The IS-EUP is displaced inferiorly, laterally, or posteriorly (Figure $7 \mathrm{C})$. 


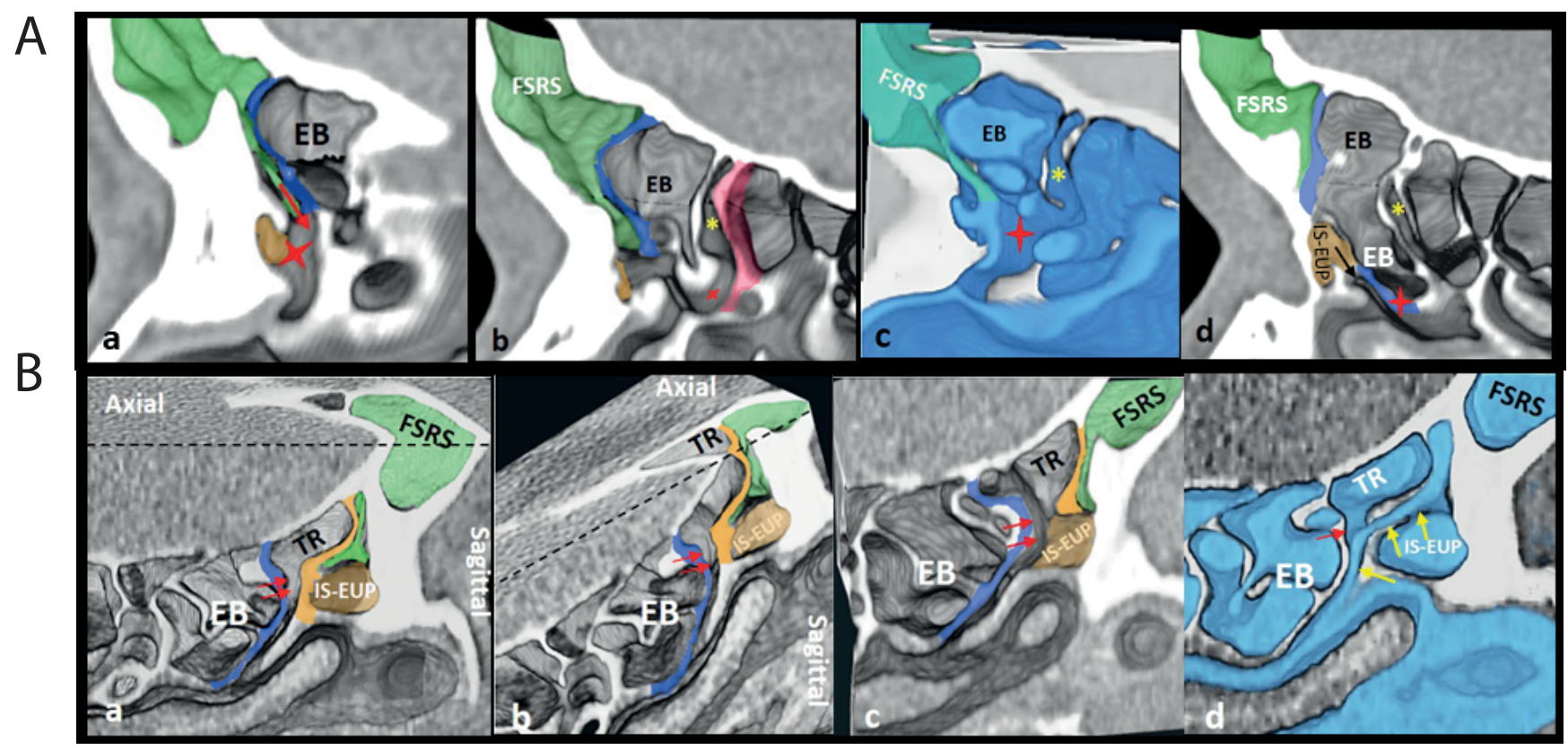

Figure 6. The "contracted/diminished" Frontal Recess.

A. The "contracted/diminished" Frontal Recess altered by the Bulla Lamella.

a.-d. 3D sagittal images in sequence from medial to lateral (right side), show the Bulla Lamella (blue outline), and the Ethmoid Bulla space (EB), expanding anteriorly into the FSRS (green outline). The FSRS drains directly (red arrow) into the Middle Meatus (red star). The IS-EUP (gold outline) is diminished in size, and drains directly into the Turbinal Infundibulum (black arrow). The retro-bullar recess space (yellow star) drains directly into the middle meatus (red star). Purple outline: basal lamella of the middle turbinate.

B. The "contracted/diminished" Frontal Recess, altered by the Uncinate Lamella.

a.-d. 3D sagittal images (left side) sequentially from medial to lateral. A Terminal Recess space (TR) is created between the antero-superiorly extending UL (gold outline), and the bulla lamella arising from the ethmoid uncinate roof superiorly fusing with the skull base with the posterior border being the BL (blue outline). The TR space diminishes the frontal recess, as it extends to the posterior FS (FSRS, green outline) and drains into the El (red arrows). Fig. $d$, shows the air spaces within the anterior ethmoid sinus, the FSRS, the TR space draining into the El (red arrow), and the FSRS draining postero-medially into the middle meatus (yellow arrows).

The Frontal Sinus/Frontal Recess Space (FSRS), and the Frontal Sinus "Ostium/Opening".

According to Schaeffer the FR is the "anlage" of the FS (17). We define the borders as follows: anteriorly, the inner table of the frontal bone; laterally, the lamina papyracea; medially, the lateral lamella of the cribriform plate and the antero-superior middle turbinate/middle meatus; posteriorly, predominantly the bulla lamella and less frequently a superiorly extending uncinate or common lamellae (group 6). In most instances the roof of the ISEUP is the floor of the FR (Figures 1-4), with exceptions demonstrated in Figures 5-7.

The plane of separation between FS and FR has had elusive definitions. Hajek states that "the ostium of the frontal sinus is first formed by the articulation of the frontal bone to the ethmoid bone (23). Lund et al. state: "there seems to be a narrowing at the transition from the posterior FS to the anterior FR, reported to be best identified on the sagittal CT images, however, the plane of "narrowing/ostium" defies an accepted definition (8). Wormald and Kew state: "the FSDP classification hinges on the definition of the frontal ostium or opening, and that the frontal ostium is defined as the narrowest area of the transition zone from the frontal sinus to the frontal recess with its anterior edge formed by the frontal sinus beak (SNS)" (7,25). McLaughlin et al. address the imprecision in avoiding a sharp subdivision between the FS and FR and Zifer stated that "the frontal sinus infundibulum, frontal sinus ostium, and frontal recess comprise a functional unit for drainage which has loosely been referred to as the frontal sinus outflow tract" $(37,38)$. Stammberger, Kennedy and Bolger state that "in the sagittal CT section, the frontal recess usually has the shape of an inverted funnel and at its union with the frontal infundibulum the shape resembles an hour-glass, with the constricted portion being at the level of the natural ostium of the frontal sinus, and that the floor of the FR varies and has no uniform definition" (13). Kim et al., however, question the "hour-glass theory" (41).

The 3DCTSI shows that the frontal recess merges with the posterior-inferior frontal sinus in a way that the resultant adult space is a combined/united space composed of the frontal sinus 


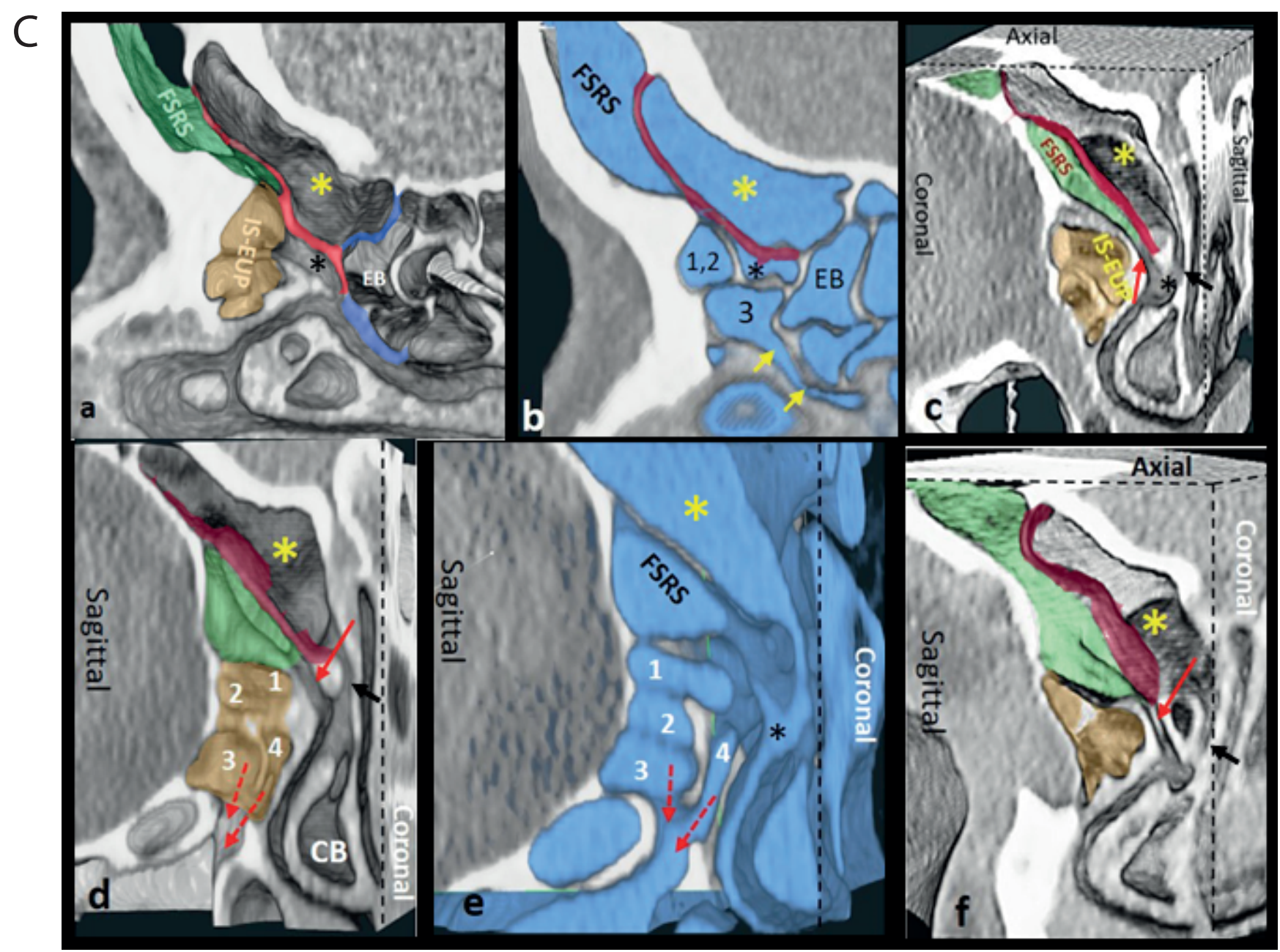

Figure 6. C. The "contracted/diminished" Frontal Recess altered by a Common Lamella.

a.-f. 3D sagittal images (Figs. a and b), and various obliquely viewed coronal 3D images (Figs. c.-f) show the prominent reduction in the size of the FSRS (green outline) as a result of the anteriorly extended common lamella (red outline), creating an interlamellar space (yellow asterisk) bordered posteriorly by the bulla lamella (blue outline), resulting in a pronounced narrowing of the FSRS (green outline, FSRS). Figs. b. and e. represent 3D images showing the air spaces (blue outline) and correspond with figs. a. and d., respectively. The FSRS (green outline) drains directly into the El (red arrow). The ILS (yellow asterisk) drains into the Middle Meatus (black arrow). IS-EUP (gold outline, spaces 1-4) drains into the TI (dashed red arrows, solid yellow arrows). CB: Concha Bullosa.

\& frontal recess (Figures 1-7). Furthermore, the communication between the FSRS and the El is through a defined direct opening, or an indirect opening from the MM through the Hiatus Semilunaris to the $\mathrm{El}$, and is absent of an inverted funnel shaped communication.

Even though the definition/localization of the plane of separation between FS/FR remains challenging, for didactic reasons, a "working definition" of this plane is imperative, given the classification groupings of the FSDP, and the specific reference to the expansion of anterior ethmoid spaces into the FR and/ or FS. Based on our observation with 3DCTSI, we propose the plane of separation between FR/FS to be the superior extension of a coronal plane along the dorsal surface of the superior nasal spine (SNS, "nasal beak") to skull base (Figure $2 \mathrm{~A}, \mathrm{C}$ ).
The Frontal Sinus Drainage Pathway(s) (FSDP): The 3DCTSI shows that an opening affording mucus drainage and air exchange from the FS is through the FR, medial and directly into the Middle Meatus (MM). This was the case in all the 7 groups above described. The communication varies as it can be focal anterior, posterior, or along the length of the inferomedial FR (Figures 1-7). Note is to be made that our use of the word drainage refers to the opening in a defined space, affording mucus drainage and air exchange from that space.

The FSRS also communicates and empties into the Ethmoidal Infundibulum (El), directly, or indirectly when the middle meatus joins the El usually distal to the fused "suprainfundibular plate" ${ }^{(23)}$, between UL and BL, or as referred to by Bolger as the "genulike" feature in the anterior ethmoid ${ }^{(39)}$ (Figures 2-7). The FSRS 
A

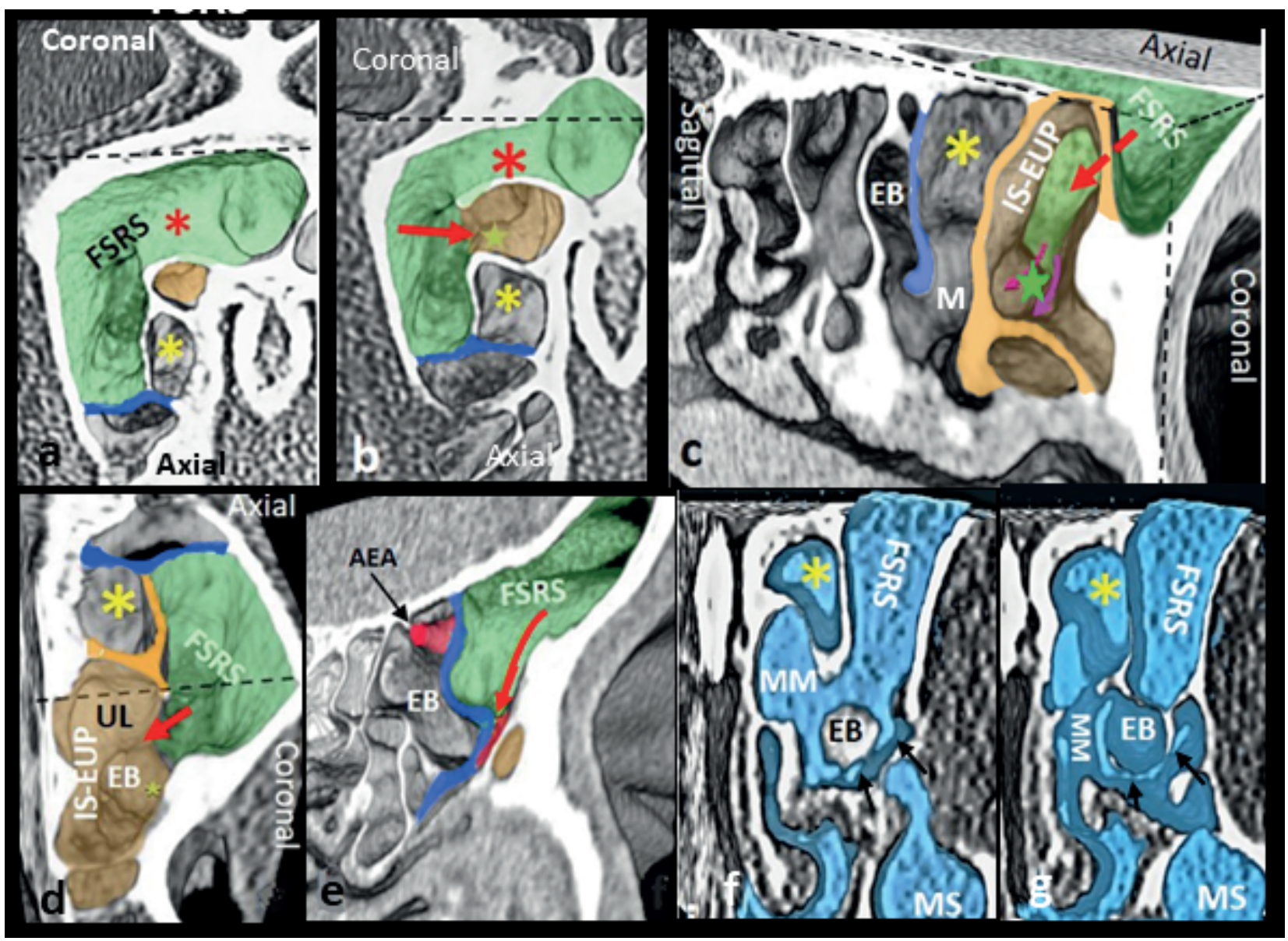

Figure 7. The pronounced inferior/anterior/medial/lateral expanding FSRS.

A. 1. The inferior/postero-lateral expanding FSRS.

a.-b. 3D axial images (left side) show the anterior/lateral and inferior depth of the FSRS space (green outline) and the direct large communication with the lateral IS-EUP (red arrow). Note the space posterior to the IS-EUP (yellow asterisk) bordered posteriorly by the Bulla Lamella (blue outline), and anteriorly by the UL (red asterisk) representing an Inter-Lamellar Space.

c. 3D sagittal image, shows the opening in the lateral outline of the EUP (gold outline), affording direct communication with the FSRS (red dashed arrow). Note the ILS (yellow asterisk) communicating with the MM (M); Ethmoid Bulla (EB); anterior tip of Ethmoid Bulla (green star); communication with the EI (purple arrows); and gold outline (IS-EUP).

d., e. 3D obliqued coronal (Fig. d) and 3d sagittal image (Fig. e), reveal the inferior depth of the FSRS (green outline), and the antero-lateral course of the uncinate lamella (gold color, UL) which surrounds the ILS (yellow asterisk). Note the anteriorly extending Ethmoid Bulla (EB) in both images; the communication between FSRS and IS-EUP (red arrow); the direct lateral communication between the FSRS and the El (red curved arrow); Anterior Ethmoid Artery (AEA, red outline), BL (blue outline).

f., g. Obliqued 3D coronal images viewed from anteriorly reveal the air spaces (blue outlines) within the anterior ethmoid sinus, the FSRS, and the FSDP: the ethmoid infundibulum surrounding the tip of the EB (black arrows); Middle Meatus (MM); ILS (yellow asterisk); Maxillary Sinus (MS).

sometimes communicates through an opening in the IS-EUP roof directly into the IS-EUP space, with clearance into the nasal cavity through the TI and MM (Figure 7). The TI mucociliary drainage pathway is posterior into the nasal cavity through the Hiatus Semilunaris into the MM, and communicates directly and inferiorly with the maxillary sinus.

Note is made that identifying the precise course of the FSDP from the FSRS into the anterior ethmoid sinus can be challenging, when dealing with $2 \mathrm{DCT}$, as well as 3DCTSI, especially in complex cases. To improve the display of the FSDP we were able to create a 3D CT display of the air within the FSRS, the IS-EUP, the EB, spaces, the maxillary sinuses as well as the FSDP, thus highlighting the drainage pathways and their association with the respective anterior ethmoid spaces. These air spaces are in blue color and appear in Figures 1-7.

\section{Conclusions}

Since the early publications by Van Alyea, Schaeffer, and others 


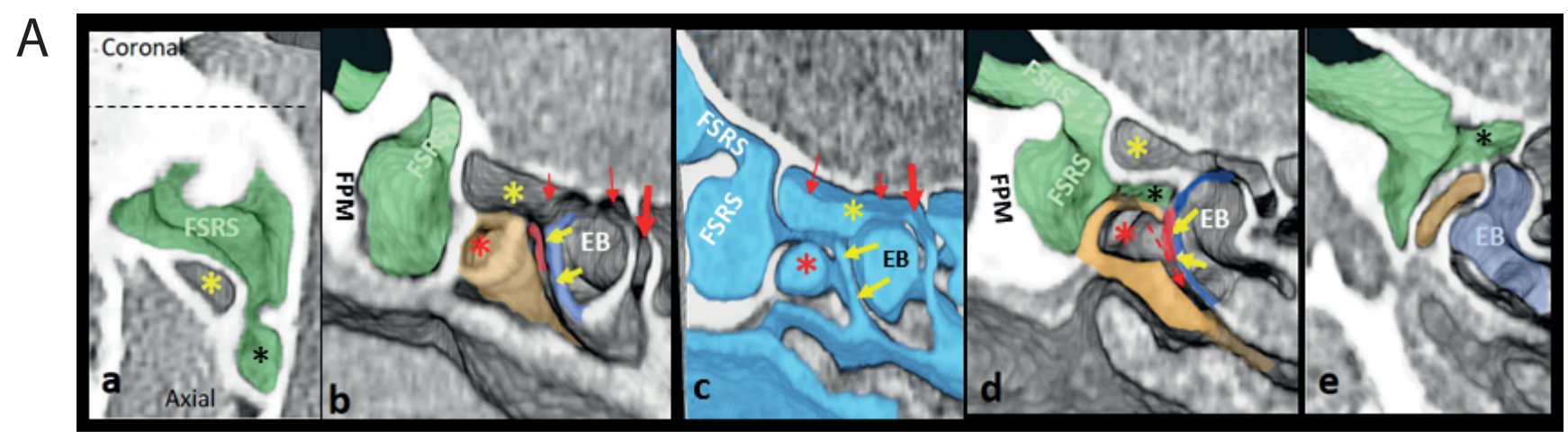

Figure 7. The pronounced inferior/anterior/medial/lateral expanding FSRS.

A. 2. The infero-anterior and lateral-medial expanding FSRS.

a.-e. 3D oblique axial image (Fig. a) and sagittal images (right side) shown sequentially from medial to lateral, reveal the expansion of the FSRS (green outline) postero-laterally, and antero-medially expanding between the frontal process of the maxilla (FPM) and the anterior EUP (gold outline) / anterior supra bulla recess space (yellow asterisk). Note the communication of the SBS (yellow asterisk, smaller red arrows) with the RBS (larger thicker red arrows). The posteriorly extending FSRS (black asterisk) directly communicates with the El (red outline; yellow arrows). The IS-EUP (red asterisk) directly communicates with the TI (red dashed arrow). Fig. c. shows the 3-dimensionality of the air spaces (blue outlines) within the FSRS and anterior ethmoid spaces correlating with Fig. b.

${ }^{(15-24)}$, a confusion seems to have permeated the terminology used to describe the anatomy. In an effort to "clarify the confusion," international panels of experts convened in 1991, 2011, and 2014 (7,8,13,14), and a number of classifications were published to clarify the relationship between the anterior ethmoid sinus and the FSDP ${ }^{(1-9)}$. These classifications, however, were based on the information provided by two-dimensional CT images. This deficit is addressed with newly available 3DCTSI in this presentation. The additional observations presented are designed to further clarify the complexity of the "spatial configuration" of the anterior ethmoid sinus, the FS, and the FSDP and facilitate the planning and performance of minimally invasive surgical procedures to further minimize surgical trauma and scar-related side effects.

\section{Authorship contribution}

SJZ, FAK, DK, AL, NN, and WH contributed to the writing and edited the anatomic detail; MS assisted in creating the needed images.

\section{Acknowledgments}

The evaluation of the nasal cavity and paranasal sinuses with 3DCTSI began in 2017 with Heinz Stammberger. The project began and benefited from Heinz's enthusiasm. His passing in
2019 left a large void in our team. His enthusiasm and pursuit for continued improvement in the display and understanding of the nasal anatomy is an inspiration in our work as it is carried forward. We miss him as a friend and teacher.

\section{Funding}

None

\section{Ethics approval and consent to participate Not applicable}

\section{Consent for publication}

Not applicable

\section{Availability of data and materials \\ Not applicable}

\section{Conflict of interest}

W.Hosemann is a consultant for Karl Storz; D.Kennedy is a consultant for Medtronic and Fiagon companies; N.London receives research funding from Merck; A.Lane is on the advisory board for Sanofi/Regeneron.

F.Kuhn, and S. Zinreich have no conflicts of interest.

\section{References}

1. Hosemann W, Kuhnel T, Weber R. Anatomy of the Paranasal Sinuses and Anterior Skull Base, Fundamentals of Endoscopic Sinus Surgery. Endo Press. 2020: 1-154 ISBN 978-

\section{3-89756-237-0}

2. Kuhn FA, Bolger WE, Tisdal RG. The Agger Nasi Cell in Frontal Recess Obstruction: An Anatomic, Radiologic and Clinical Correlation. Operative Techniques in
Otolaryngology-Head and Neck Surgery. 1991;2(4):226-31.

3. Bent JP, Cuilty-Siller C, Kuhn FA. The frontal cell as a cause of frontal sinus obstruction. Am J Rhinology. 1994;8(4):185-91. 


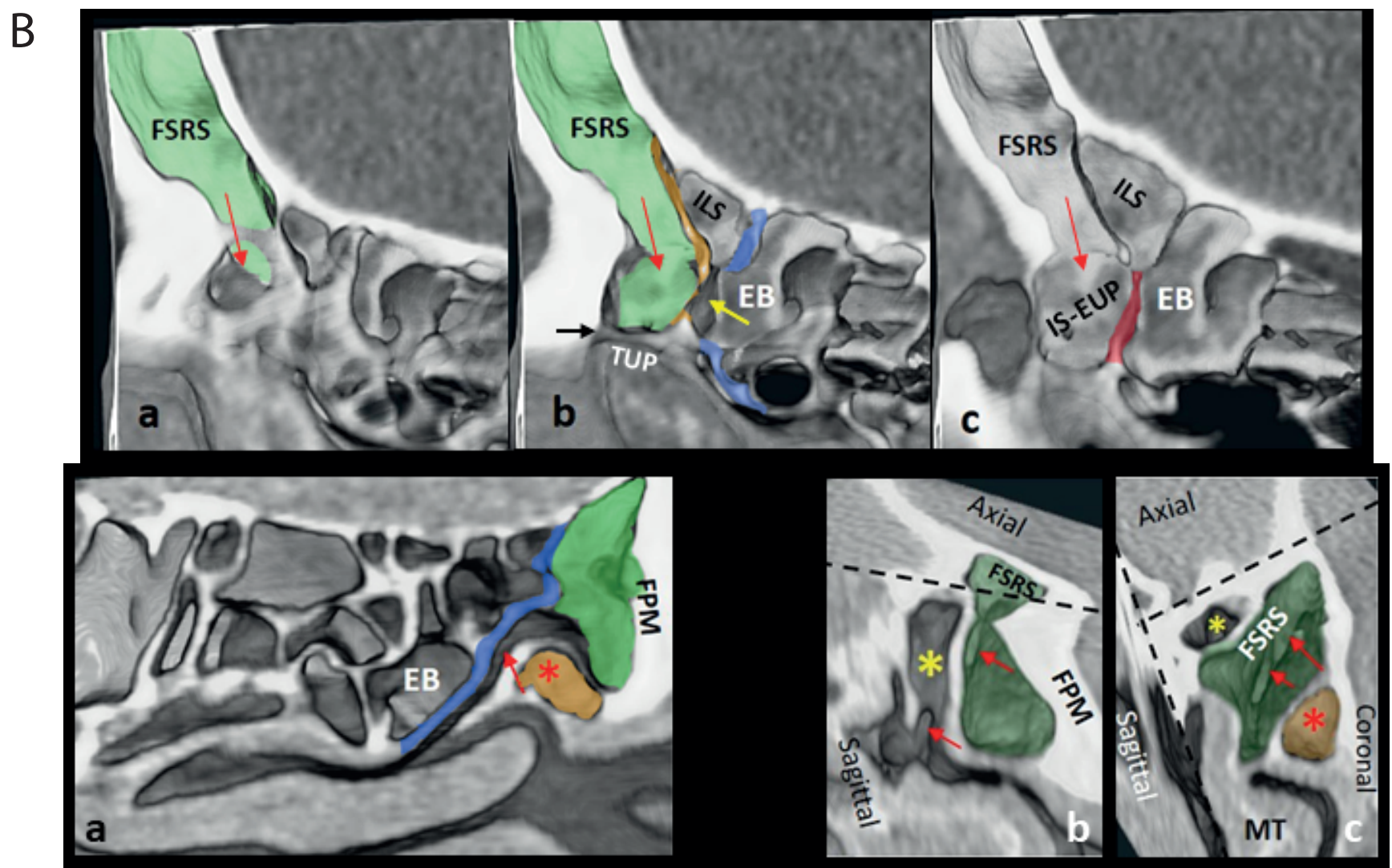

Figure 7. The pronounced inferior/anterior/medial/lateral expanding FSRS.

B.1 The inferior expanding FSRS through opening in roof of IS-EUP.

a.- c. 3D sagittal images (right side) shown sequentially from medial to lateral, reveal the inferior extension of the FSRS (FSRS, green outline), through a large opening in the roof of the EUP (red arrow) with direct communication with the IS-EUP reaching the superior turbinal uncinate process (TUP, black arrow). Note the superior uncinate reaching the skull base, is the anterior border of an Inter-Lamellar Space (ILS) bordered posteriorly by the Bulla Lamella (blue outline), and communicating inferiorly with the Middle Meatus (yellow arrow). Common Lamella (red outline).

B.2 Examples of inferior expanding FSRS displacing, without invading the IS-EUP roof.

a. 3D sagittal image (left side) shows the prominent inferior extension of the FSRS to the superior TUP, with posterior displacement of the IS-EUP (gold outline). Note the direct communication of the FSRS to the El (red arrow). Bulla Lamella (blue outline). b. and c. Different patients (left side) with the FSRS (green outline extending inferiorly to the level of the superior TUP, with inferolateral displacement of the IS-EUP (gold outline). Note the lateral direct communication with the El (red arrows). Yellow asterisk: interlamellar space.

4. Lee WT, Kuhn FA, Citardi MJ. 3D computed tomographic analysis of frontal recess anatomy in patients without frontal sinusitis. Otolaryngol Head Neck Surg. 2004;131(3):164-73.

5. DelGaudio JM, Hudgins PA, Venkatraman G, Beningfield A. Multiplanar computed tomographic analysis of frontal recess cells: effect on frontal isthmus size and frontal sinusitis. Arch Otolaryngol Head Neck Surg. 2005;131:230-5.

6. Wormald PJ. Anatomy of the frontal recess and frontal sinus with three-dimensional reconstruction. In: Wormald PJ (ed.) Endoscopic sinus surgery: anatomy, threedimensional reconstruction and surgical technique, 3rd edn. Thieme, New York, 2013.

7. Wormald PJ, Hoseman W, Callejas C, et al.
The International Frontal Sinus Anatomy Classification (IFAC) and Classification of the Extent of Endoscopic Frontal Sinus Surgery (EFSS). Int Forum Allergy Rhinol. 2016 Jul;6(7):677-96.

8. Lund VJ, Stammberger H, Fokkens WJ, et al. European position paper on the anatomical terminology of the internal nose and paranasal sinuses. Rhinol Suppl. 2014 Mar;24:1-34.

9. Altunay ZA. Onerci TM. Analysis of type IV frontal cell on an embryological basis. B-ENT 2020; 16(3):153-7.

10. Zinreich SJ, Stammberger H, Bolger W, et al. Advanced $C T$ imaging demonstrating the bulla lamella and the basal lamella of the middle turbinate as endoscopic landmarks for the anterior ethmoid artery. Rhinology
Online. 2019;(2):32-43

11. Zinreich SJ, Kuhn FA, London NR, et al. 3DCT stereoscopic imaging: an improved anatomical understanding of the anterior ethmoid sinus and frontal sinus drainage pathway. Rhinology Online. 2020;(3):202-20.

12. Stammberger $\mathrm{H}$. The Messerklinger technique. In: Stammberger $H$, editor. Functional Endoscopic Sinus Surgery. Philadelphia: BC Deckker, 1991.

13. Stammberger HR, Kennedy DW, Bolger W, et al. Paranasl sinus: anatomic terminology and nomenclature. Ann Otol Rhinol Laryngol Suppl. 1995;167:7-16.

14. Terminologia Anatomica - International Terminology: Thieme Medical Publishers, Incorporated, 2011.

15. Seydel O. Über die Nasenhöhle der höheren 
Säugetiere und des Menschen. Morphol Jahrb. 1891(17):44-99.

16. Zuckerkandl E. Normale und pathologische Anatomie der Nasenhöhle und ihrer pneumatischen Anhänge [Normal and Pathologic Anatomy of the Nasal Cavity and its Pneumatized Annexes], Band 1 and 2. Braumuller, Vienna 1882, 1892.

17. Schaeffer JP. The genesis, development and adult anatomy of the nasofrontal region in man. Am J Anatomy. 1916;(20):125-46.

18. Grunwald L. Die Lehre von den Naseneiterungen [Teachings of nasal suppurations]. Lehmann, Munich, 1926.

19. Layton TB. Preface to Catalogue of the Onodi Collection, Royal College of Surgeons of England. 1934:i-xx

20. Van Alyea OE. Frontal Cells - An anatomic study of these cells with consideration of their clinical significance. Arch Otolaryngol. 1941;34(1):11-23.

21. Van Alyea OE. Ethmoid Labyrinth: Anatomic study with consideration of the clinical significance of its structural characteristics. Arch Otolaryngology. 1939:29:881-902.

22. Dorland's Illustrated Medical Dictionary. 23rd Edition, W.B. Saunders Company, 1951.

23. Hajek M. Pathologie und Therapie der entzündlichen Erkrankungen der Nebenhöhlen der Nase [Pathology and therapy of inflammatory diseases of the paranasal sinuses]. 5th ed.; Deuticke, Leipzig and Vienna 1926

24. Lang J. Clinical Anatomy of the Nose, Nasal Cavity and Paranasal Sinuses.Thieme;1989.

25. Kew J, Rees GL, Close D, et al. Multiplanar reconstructed computed tomography images improves depiction and understanding of the anatomy of the frontal sinus and recess. Am J Rhinol. 2002;16:119-123.

26. Jacobs B, Lebowitz RA, Sarin A, Hariri S. Preoperative Sagittal CT Evaluation of the Frontal Recess. Am J of Rhinol. 2000;14:33-7.

27. Arun G, Sanu PM, Mohan M, et al. Anatomical variations in superior attachment of uncinated process and localization of frontal sinus outflow tract. Int J Otorhinolaryngol Head Neck Surgery. 2017;3(2):176-9.

28. Netto B, Piltcher OB, Meotti CD, Lemieszek J, Isolan GR. Computed tomography imaging study of the superior attach- ment of the uncinate process. Rhinology. 2015;53(2):187-91

29. Landsberg R, Friedman M. A computerassisted anatomical study of the nasofrontal region. Laryngoscope. 2001;111(12):212530.

30. Mahmutoğlu AS, Çelebi I, Akdana B, et al. Computed tomographic analysis of frontal sinus drainage pathway variations and frontal rhinosinusitis. J Craniofac Surg. 2015 Jan;26(1):87-90

31. Bolger WE, Butzin CA, Parsons DS. Paranasal sinus, bony anatomic variations and mucosal abnormalities: CT analysis for endoscopic sinus surgery. Laryngoscope. 1991;101:56-64.

32. Ercan I, Cakir BO, Sayin I, et al. Relationship between the superior attachment type of uncinate process and presence of agger nasi cell: a computer-assisted anatomic study. Otolaryngol Head Neck Surg. 2006 Jun;134(6):1010-4

33. Kuhn FA. Chronic frontal sinusitis: the endoscopic frontal recess approach. Operative Techniques. Otolaryngol Head and Neck Surg. 1996;7:222-9.

34. Landsberg R, Friedman M. A computerassisted anatomical study of the nasofrontal region. Laryngoscope. 2001;111(12):212530.

35. Lee WT, Kuhn FA, Citardi MJ. 3D computed tomographic analysis of frontal recess anatomy in patients without frontal sinusitis. Otolaryngol Head Neck Surg. 2004:131(3):164-73.

36. Park SS, Yoon BN, Cho KS, Roh HJ Pneumatization Pattern of the Frontal Recess: Relationship of the Anterior-toPosterior Length of Frontal Isthmus and/ or Frontal Recess with the Volume of Agger Nasi Cell. Clin Exp Otorhinolaryngol. 2010;3(2):76-83.

37. McLaughlin RB Jr, Rehl RM, Lanza DC Clinically relevant frontal sinus anatomy and physiology. Otolaryngol Clin North Am. 2001 Feb;34(1):1-22.

38. Zeifer B. Update on sinonasal imaging anatomy and inflammatory disease. Neuroimaging Clin North Am. 1998 August;8(3):607-30

39. Bolger WE, Stammberger $\mathrm{H}$, Ishii $M$, et al. The Anterior Ethmoidal "Genu": A newly appreciated Anatomic Landmark for Endoscopic Sinus Surgery. Clin Anat. 2019 May;32(4):534-40.

40. Rusu MC, Sava CJ, Ilie AC, Săndulescu M, Dincă D. Agger nasi cells versus lacrimal cells and uncinate bullae in cone-beam computed tomography. EarNose Throat J. 2019 Jul;98(6):334-9.

41. 41. Kim KS, Kim HU, Chung IH, Lee JG, Park IY, Yoon JH. Surgical anatomy of the nasofrontal duct: anatomical and computed tomographic analysis. Laryngoscope. 2001 Apr;111(4 Pt 1):603-8.

42. Terrier $F$, Terrier $G$, Rüfenacht $D$, et al. Die Anatomie der Siebbeinregion: topographische, radiologische und endoskopische Leitstrukturen [Anatomy of the ethmoid bone region: topographical, radiological and endoscopic landmarks]. Ther Umsch. 1987:44(2):75-85.

43. Márquez S, Tessema B, Clement PA, Schaefer SD. Development of the ethmoid sinus and extramural migration: the anatomical basis of this paranasal sinus. Anat Rec (Hoboken). 2008 Nov;291(11):1535-53.

44. Pianta L, Ferrari M, Schreiber A, et al. Aggerbullar classification $(A B C)$ of the frontal sinus drainage pathway: validation in a preclinical setting. Int. Forum Allergy Rhinol. 2016;(6):981-9.

45. Thomas L, Pallanch JF. Three-dimensional $C T$ reconstruction and virtual endoscopic study of the ostial orientations of the frontal recess. Am J Rhinol Allergy. 2010 SepOct:24(5):378-84.

\section{S.J. Zinreich}

The Russel H. Morgan Departments

of Radiology

The Johns Hopkins Medical Institu-

tions

Baltimore

MD, USA

E-mail: sjzinreich@jhmi.edu

ISSN: 2589-5613 / @ 2021 The Author(s). This work is licensed under a Creative Commons Attribution 4.0 International License. The images or other third party material in this article are included in the article's Creative Commons license, unless indicated otherwise in the credit line; if the material is not included under the Creative Commons license, users will need to obtain permission from the license holder to reproduce the material. To view a copy of this license, visit http://creativecommons.org/licenses/by/4.0/ 